\title{
Os vários mundos do financiamento da Saúde no Brasil: uma tentativa de integração
}

\author{
H ealthcare financing options in Brazil: an attempt at integration
}

1 Instituto de M edicina Social, Universidade Estadual do Rio de Janeiro. Rua São Francisco Xavier 524, Pavilhão João Lyra Filho, 70 andar, blocos D e E, M aracanã. 20550-900 Rio deJaneiro RJ. sulamis@uol.com.br
Abstract This paper addresses the dilemma underlying H ealthcarefinancing, caught between the long-term view proposed by the Social Security segment in 1988 and the short-term view imposed by a series of fiscal adjustments, hampering the expansion of healthcare resources in Brazil. Within the context of Constitutional Amendment $\mathrm{N}$ o 29, the extension of the Provisional Financial Transactions Levy (CPM F), the Federal Funds Earmarking Removal Provision (DRU), and forthcoming tax reforms, aspects of the taxation system, social security dues, subsidies, incentives and tax revenue waivers are examined, also exploring political and institutional aspects of intergovernmental relationships and the links between the public and private sectors, in terms of H ealthcare financing. This paper spotlights the headroom available for stepping up the financing levels of Brazil's National Health System (SU S), in order to bridge public health gaps and even out inequalities in nationwide service supplies. A review of intergovernmental relationships and the links between the public and private sectors is also suggested. Finally, positive aspects of Government spending are presented, together with financing tools for this sector that would spur the economic and technological development of Brazil.

Key words Brazil, Financing for Brazil's National Health System (SUS), Constitutional amendment 29, Healthcare economics
Resumo 0 artigo aborda o dilema subjacenteao financiamento da Saúde, entre a visão de longo prazo proposta pela SeguridadeSocial em 1988, e a visão de curto prazo, centrada nos sucessivos ajustes fiscais, quevem frustrando a expansão de recursos da Saúde no Brasil. No contexto da regulamentação da Emenda Constitucional 29, da renovação da CM PF eda DRU, e de uma próxima reforma tributária, são tratados aspectos do sistema tributário, das contribuições sociais, dos subsídios, incentivos e renúncia de arrecadação. Considera também aspectos político-institucionais das relações intergovernamentais e das relações entre o setor público e o setor privado, presentes ao financiamento da Saúde. 0 trabaIho torna evidente a existência de espaço para ampliar o patamar definanciamento do SU S, de modo a superar os vazios sanitários, bem como as desigual dades de oferta de servi ços no território. Sugere também a revisão das relações financeiras intergovernamentais e entre o setor público e 0 setor privado. Finalmente, apresenta aspectos virtuosos do gasto público e dos instrumentos de financiamento do setor para o desenvolvimento econômico e tecnológico do Brasil. Palavras-chave Brasil, Financiamento do SU S, EC 29, Economia da saúde 


\section{Introdução}

Este trabal ho acompanha a evolução do SUS do ponto de vista de seu padrão de financiamento, integrando as várias dimensões nas quais se desdobra esta análise. Com esta intenção, são destacadas as relações entre a política fiscal e da Seguridade Social, o conjunto das relações intergovernamentais e finalmente as relações entre o setor público e o setor privado.

Do ponto de vista da necessidade incontornável da população por mais e melhores ações e serviços públicos de saúde, éessencial que o SUS possa al cançar novo patamar de gastos, compatível com a superação dos vazios sanitários ecom as desigualdades regionais e setoriais que ainda caracterizam o acesso e a utilização de serviços produzidos pelo sistema. No marco dos avanços do SUS, é importante ressaltar as tendências de conformação de novos padrões de financiamento da Saúde, caracterizados pela combinação de financiamento público, universalização do acesso e aperfeiçoamento da gestão com uma provisão autônoma, indiferentementeestatal e/ou privada dos serviços.

0 trabalho destaca também a esfera das relações público-privadas no campo da Saúde, onde floresce o espaço da renúncia de arrecadação, ou do financiamento indireto pelo Estado, de planos e seguros de saúde. Estes são incentivados por tratamentos tributários favorecidos a pessoas físicas e jurídicas, assim como aos próprios sistemas de saúde supletiva, sem que se possa dar visibilidade orçamentária a tais gastos indiretos do Estado. Além do mais, a ausência ou insuficiência de regulação deste segmento compromete a política nacional de saúde.

O financiamento público da Saúdeétambém responsável pelo entrelaçamento virtuoso da política social e da política de desenvolvimento. Pelo poder de compra da Saúde, o Estado pode exercer sua capacidade regulatória e de fomento sobre o setor produtivo, no campo dos medicamentos, insumos estratégicos e equipamentos, participando assim da fronteira científica e tecnológica nacional, ampliando por outro lado o acesso da população aos medicamentos necessários através de uma política de assistência farmacêutica pública. Há espaço para uma nova investida a favor do fortalecimento do SUS, invertendo a cadeia de determinação perversa entreo econômico e o social quetanto tem prejudicado a universalização da Saúde.
A luta pela estabilidade e suficiência de recursos para o SUS: da seguridade social à emenda constitucional 29

Há quase vinte anos, o Sistema Ú nico de Saúde brasileiro apresenta dificuldades em garantir recursos estáveis e suficientes para o seu financiamento. No período, alternaram-se fontes de receitas, impostos e contribuições sociais, sem ampliar a participação do gasto do SU S no Produto Interno Bruto ou na receita tributária como um todo. Isso ocorre em flagrante descompasso com as responsabilidades impostas pela universalização do sistema e seu reflexo sobre o gasto público em Saúde.

0 processo de unificação das ações e serviços públicos de saúde em programa de acesso universal e de direito da cidadania foi consagrado na Constituição Federal de 1988, quando a Saúde, juntamente com a Previdência e a Assistência Social, passou a compor o campo da proteção social no Brasil. Ao combinar direitos individuais e coletivos, ou contribuintes e cidadãos num mesmo programa, a nova visão de proteção social integrou padrões distintos de financiamento, baseados em impostos e contribuições sociais e recursos de dois orçamentos, o OGU e o Orçamento da Seguridade Social ${ }^{1}$.

O Orçamento da Seguridade Social (OSS) representava a precedência da cobertura dos direitos sociais sobre a disponibilidade de recursos ${ }^{1}$, tornando impositiva a busca de novas fontes e a ampliação das receitas vinculadas aos programas que o integravam.

Os programas universais justificaram, no capítulo da Ordem Social, a autorização para a diversificação das fontes da Seguridade. As necessidades de financiamento das políticas universais destinadas a prover gastos não individualizados, como os serviços de Saúde, acrescentaram à tradicional folha de salários, basecentral do financiamento previdenciário, o aportedecontribuições sociais gerais (COFINS, PIS-PASEP e CSLL - as três áreas da Seguridade sempre trataram seus campos administrativos e financeiros de forma independente, apoiados em fortelegislação infraconstitucional. O SU S foi regulamentado pela Lei Orgânica da Saúde Lei 8.080 de setembro de 1990 e pela lei 8.142 de dezembro do mesmo ano).

A composição inicial do OSS - sem vincular fontes para cada área específica - contemplou a natureza distinta dos benefícios e serviços, prevendo, além das fontes supracitadas, 0 aporte de recursos fiscais do Tesouro a fundo perdido ${ }^{2}$. 
Do ponto de vista das relações financeiras intergovernamentais, a criação do SUS materializou o esquema tripartite de financiamento federativo da Saúde, pretendendo integrar os recursos federais do OSS e do OGU aos recursos fiscais de estados e municípios ${ }^{9}$ ( 0 art. 198, § 10 da CF de 1988 definiu o financiamento da Saúde pelo Orçamento da SeguridadeSocial - OSS, nos três níveis de governo. Até a edição da primeira LDO (1990), o Art. 55 do Ato das Disposições Constitucionais Transitórias - ADCT destinava $30 \%$ do OSS para a Saúde). N o processo de competição por recursos, os programas universais, com menor capacidade de defesa, foram sendo progressivamente isolados na luta pelo acesso às fontes de receita vinculadas pela Constituição ao seu financiamento.

A partir de 1990, verificou-se, de forma cada vez mais acentuada, a não observância do artigo 55 do ADCT, já mencionado, que regia os repasses do M PAS ao M S. Em 1993, sob a al egação de restrições fiscais e de aumento das despesas da Previdência Social, os recursos originários da foIha de salários deixaram de ser repassados ao M inistério da Saúde, passando a financiar exclusi vamentea Previdência Social.

A interrupção do aporte desses recursos para a Saúde gerou grandeinstabilidadenos anos subseqüentes, aumentando a dependência da saúde em relação a outros recursos do Tesouro Nacional. Ainda em 1993, com o intuito de dar estabilidade esuficiência ao financiamento da Saúde, a PEC 169 encaminha Proposta de Vinculação Constitucional "Definitiva" de $30 \%$ do OSS, a ele acrescentando $10 \%$ da receita de impostos da União, Distrito Federal, estados e municípios.

0 crescimento de receita por conta das novas contribuições sociais e da ampliação das préexistentes foi parcialmente neutralizado pela desvinculação das receitas da União, através do Fundo Social de Emergência (FSE), que vigorou em 1994 e 1995, posteriormente renomeado como Fundo de Estabilização Fiscal (FEF), entre 1996 a 1999.

A estratégia de desvinculação de recursos vem sendo mantida desde então, através da Desvinculação de Receitas da União (DRU), que, como os dispositivos anteriores, captura $20 \%$ da arrecadação de impostos e contribuições da União, (com exceção dos Fundos de Participação e da contribuição sobre a folha de salários).

$\mathrm{N}$ a segunda metade da década de 90 , dada a irregularidade dos aportes de receita ao OSS, 0 M S encampa e lidera a luta pela criação de uma fonteespecífica definanciamento para a Saúde, a
Contribuição Provisória sobre a M ovimentação Financeira (CPM F).

A provada no final de 1996 e implantada em 1997, a CPM F não gerou o aumento de recursos esperado, por ter sido acompanhada pela substituição de fontes, decrescendo a importância da CSLL e da COFINS no orçamento do MS. Em 1999, a CPM F deixa deser fonteexclusiva da Saúde, passando a financiar a Previdência e, a partir de 2001, o Fundo de Combate à Pobreza³.

Após várias reformulações ao longo de sete anos, a EC 29 foi aprovada em 13 de setembro de 2000. Com isso, o sistema de financiamento da Saúde ganhou maior estabilidade uma vez que foram estabelecidos patamares mínimos de aplicação de recursos da União, dos estados e dos municípios no apoio ao SUS.

No caso da União, passou a vigorar o montanteaplicado no ano anterior, corrigido pela variação nominal do PIB. Para estados e municípios, a base de cálculo passou a ser a receita tributária própria e detransferências. Foi estabelecido o aumento gradual da vinculação da receita tributária de estados e municípios a partir do mínimo de $7 \%$ em 2000, atéos $12 \%$ e $15 \%$, respectivamente, em 2004, de acordo com as resoluções nos 316 e 322 do CN S.

0 movimento em torno à defesa da EC 29 articulou atores políticos e entidades e estimulou a discussão em torno aos pontos polêmicos da proposta, como as alternativas de base de cálculo para a vinculação e o próprio conceito de despesas em saúde. Consideram-se despesas com ações e serviços públicos de saúde aquelas com pessoal ativo e outras despesas de custeio e de capital, financiadas pelas três esferas de governo, conforme o disposto nos artigos 196 e 198, § 2ㅇ, da Constituição Federal ena Lei no 8080/90, relacionadas a programas finalísticos e de apoio, inclusive administrativos, que sejam destinadas às ações e serviços de acesso universal, igualitário e gratuito; estejam em conformidade com objetivos e metas explicitados nos Planos de Saúde de cada ente federativo e sejam de responsabilidade específica do setor de saúde.

A EC 29 deveria promover a blindagem do sistema, em termos da sustentabilidade e suficiência de recursos, avançando também na solidariedade federativa através da definição de parâmetros para o estabelecimento de relações fiscais intergovernamentais no SUS.

A pesar do apoio em torno à emenda, aos seus desdobramentos legais eà sua normatização, não se materializaram as expectativas de um aumento mais substantivo do gasto federal em saúde. 
De outro lado, no plano federal, a EC 29 reforçou a tendência à definição de soluções específicas definanciamento dentro do $\mathrm{OSS}^{3}$, além de dissociar a Saúde dos expressivos aumentos da receita das contribuições sociais. A União passou a beneficiar-se do dinamismo destas contribuições, sem a ele associar a expansão de gastos universais da seguridade.

Sebem seja verdadequea EC 29 teve o inegável mérito de comprometer efetivamente as três esferas de governo com a universalização da saúde, é bom lembrar que, no plano federal, procedeu-se à desvinculação da Saúde do Orçamento da Seguridade Social. A EC 29 não defineas fontes que devem financiar a Saúde e sim a variação de seu gasto pelo crescimento do PIB nominal ( no campo específico da Saúde, os repasses para o M S, originários das receitas administradas pela Secretaria do Tesouro Nacional - receitas fiscais, COFINS e CSLL - apresentaram comportamento cíclico e alternância na composição das fontes, mesmo apósa instituição da CPM F eda implantação da EC 29).

Durante todo este tempo, foi mantida a baixa participação dos investimentos na execução orçamentária do MS e não houve espaço financeiro para a existência de uma política mais ampla de correção das desigual dades de acesso, derivadas da má distribuição da oferta de serviços. A cobertura das ações e serviços do SU S manteve-se limitada e os vazios assistenciais ainda estão por superar. Nesta perspectiva, o SUS continua subfinanciado, representando menos de $17 \%$ do OSS e cerca de $5 \%$ da despesa efetiva do governo federal ${ }^{4}$.

A recente criação da Super Secretaria da Receita Federal, hoje responsável também pela administração da folha de salários, base de financiamento da Previdência Social, virtualmente unificou os dois orçamentos (OSS e OGU), reduzindo ainda mais o espaço próprio, institucional e político, da proteção social no Brasil.

$\mathrm{Na}$ prática, a dimensão universalizante do projeto da Seguridade Social brasileira foi minimizada, o que não decorre, como se afirma, de uma resposta "responsável" ao "caráter perdulário" do capítulo da Ordem Social da Constituição de 1988. A alegada crise de financiamento dosgastos da Seguridade Social não existiria se a alocação dos recursos vinculados a estes programas tivesse respeitado sua destinação constitucional.
Evolução do orçamento da Seguridade Social: onde está o déficit?

Durante os anos 2000, o gasto social como um todo explica apenas a metade do crescimento da carga tributária do governo federal, tendo sido a outra metade alocada ao superávit primário para fins de ajustefiscal. Ou seja, apesar da significativa elevação da carga tributária, de 4,37 pontos percentuais do PIB, os gastos de Saúde, no mesmo período, respondem por menos de um centésimo desta elevação da carga no período, desautorizando as freqüentes al egações de crescente participação da Saúde no total de gastos do governo federal.

$\mathrm{Na}$ Tabela 1, contrastando com o aumento de quase dois pontos percentuais da carga tributária alocado aos gastos com benefícios previdenciários durante o período, os gastos em Educação eSaúdepermanecem quaseconstantes, com apropriação de apenas 0, 02\% e 0,03 \% \%, respectivamente, da elevação da carga.

O resultado do OSS de 2006 expressa diminuição de $17 \%$ relativamente ao ano anterior e em valores relativos ao PIB (-23,3\%), interrompendo uma série ascendente de saldos superavitários. M esmo com a diminuição do superávit da SeguridadeSocial, o resultado de 2006 foi praticamente equivalente a todo 0 resultado primário do governo federal, da ordem de $R \$ 49,8$ bilhões 5 .

0 Gráfico $1^{5}$ ilustra a força do superávit gerado no OSS para fins de ajuste fiscal, no período de 2000 a 2006. Se, nos últimos sete anos, esse excedente tivesse sido investido no setor de saúde, seus recursos teriam sido ampliados em mais de $100 \%$ a.a. Para garantir este superávit, a gestão orçamentária da União vem conflitando com os interesses da Seguridade Social e impondo sucessivos contingenciamentos de recursos.

Carga tributária, impostos e contribuições sociais no financiamento da saúde

Ao centrar a análise nas possíveis fontes de financiamento da saúde, retiramos os tributosque já têm destinação exclusiva, como é o caso da receita previdenciária e do FGTS. Neste caso, a carga tributária "disponível" da União seria de 16,52\% em 2006, contra 14,35\% em 2000.

No ano de2006, as contribuições sociais criadas ou ampliadas para a viabilização do orçamento da Seguridade Social são responsáveis por mais de $50 \%$ da arrecadação da União, ain da que excluídos os recursos da previdência e do FGTS. 
Tabela 1. Apropriação do aumento da carga tributária por programa.

\begin{tabular}{lccccccc}
\hline & 2000 & 2001 & 2002 & 2003 & 2004 & 2005 & $2000-2005$ \\
\hline Vinculações universais (A) & 2,39 & 2,47 & 2,42 & 2,27 & 2,42 & 2,44 & 0,05 \\
$\quad$ Educação & 0,54 & 0,59 & 0,58 & 0,52 & 0,57 & 0,56 & 0,02 \\
$\quad$ Saúde & 1,85 & 1,87 & 1,84 & 1,75 & 1,85 & 1,88 & 0,03 \\
\hline Benefícios sociais(B) & 6,65 & 7,06 & 7,39 & 7,72 & 8,10 & 8,63 & 1,97 \\
$\quad$ Benefícios previdenciários & 5,97 & 6,28 & 6,54 & 6,88 & 7,12 & 7,54 & 1,56 \\
$\quad$ Seguro-desemprego & 0,5 & 0,55 & 0,59 & 0,55 & 0,56 & 0,61 & 0,12 \\
Assistência social & 0,18 & 0,22 & 0,26 & 0,29 & 0,42 & 0,48 & 0,30 \\
\hline Soma (A +B) B & 9,05 & 9,53 & 9,80 & 9,98 & 10,52 & 11,07 & 2,02 \\
Carga tributária federal & 22,25 & 23,52 & 25,04 & 24,23 & 25,10 & 26,62 & 4,37 \\
\hline
\end{tabular}

Elaboração própria. Fonte: STN, TCU, M inistério da Saúde.

Gráfico 1. Evolução do superávit da Seguridade Social, 2000 a 2006.

Evolução do superávit da Seguridade Social - 2000 a 2006 (em bilhões R\$).

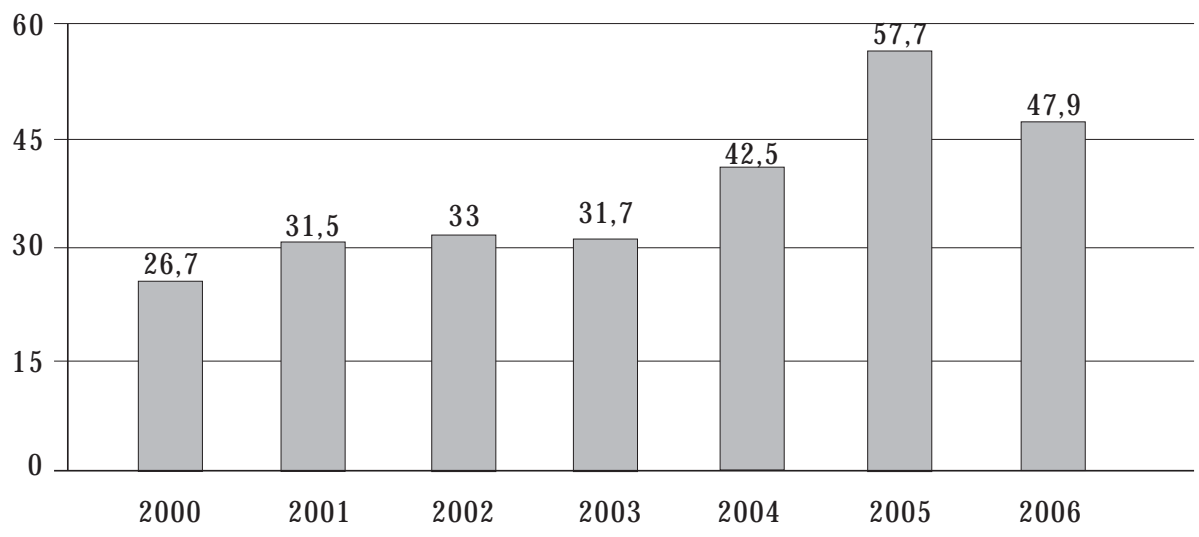

Superávit da Seguridade Social

Elaboração AN FIP. Fonte: M PSeSIAFI.

Além disso, entre 2000 e 2006, estas contribuições aumentaram em 2,46\% sua participação no total (48,45\% em 2000 e 50,91\% em 2006), enquanto os impostos perderam participação praticamentena mesma proporção - 2,47\% (45,70\% em 2000 e 43,23\% em 2006).

Em termos do financiamento da Saúde, a análise daúltima década ofereceinteressante campo de estudos, não só do ponto de vista econômico como também do ponto de vista das relações políticas no campo federativo.
As novas contribuições sociais (a COFINS, 0 PIS-PASEP, a CSLL e a CPMF) são tributos disfarçados na competência da União e promoveram, além do alargamento da capacidade de financiamento dos programas universais, ampla recentralização de recursos em mãos do governo federal. Em sua grande mai oria, significou uma volta à tributação cumulativa praticada antes de 1967, quando a criação do ICM S e do I PI substituiu grandenúmero detributosindiretos em cascata anteriormente vigentes. 
A el evação da carga global (de 29\% do PIB em 1998 para 35,9\% do PIB em 2006) foi fortemente influenciada pela evolução das contribuições sociais indiretas, que tiveram como efeito adicional a recuperação da participação federal na receita tributária disponível aos níveis dos anos 60. A participação dos municípios praticamente duplicou, em detrimento da representatividade dosestados, no total da carga tributária disponível.

Pode-se dizer que o modelo de descentralização de viés municipalista da Saúdese reproduz no plano das relações fiscais intergovernamentais, transmitindo ao pacto federativo do SUS a fragilidade fiscal dos estados brasileiros e a corrosão de sua base vinculável, nos termos da EC 29.

Como evidenciam os dados da Tabela 2, entre 2000 e 2005, apenas a receita disponível da União cresce 1,09, à custa da redução de 0,81\% e 0,28\% nas participações deestados emunicípios, respectivamente. Ao mesmo tempo, explicam a elevação da carga tributária global, onerando de forma regressiva os contribuintes, em particular os mais pobres, por serem cobrados de forma indireta e cumulativa, sobreo conjunto debense serviços produzidos e consumidos no país.

Vários estudos que estimam a carga tributária por faixa de renda a partir da Pesquisa de Orçamentos Familiares (POF) do IBGE apontam esta regressividade ${ }^{6,7}$ e revelam que os indivíduos que ganham até dois salários mínimos pagam $26 \%$ de sua renda em impostos indiretos, ao passo que os que ganham mais de trinta salários mínimos, apenas $8 \%$. Este desnível não é compensado pela tributação sobre a renda, cuja base é muito estreita. Assim, quando se somam impostos diretos e indiretos, para os que ganham mais de trinta salários mínimos, a carga tributária total alcança $18 \%$, sendo de $27 \%$ para os que ganham até dois salários mínimos. 0 impacto perverso da tributação indireta sobre as famílias se complementa com as conseqüências negativas destas modalidades de tributação sobre a competitividade da produção brasileira, relativamente aos produtos dos demais países, onde as contribuições sociais são restritas á tributação sobre a folha de salários.

Se bem quea EC 29 tornou o gasto federal de saúdeexclusivamente dependenteda evolução do PIB nominal, isso não eximeo SU S depreocupações quanto às fontes de receita que viabilizam sua expansão, notadamente a CPM F, majoritariamente destinada à Saúde. Deste ponto de vista, éimportante assinalar quea CPM F não émais injusta queas demais contribuições, uma vez que não atinge os grupos de renda mais baixos, além de ser adequada à tributação das transações financeiras, hoje subtributadas.

Sob o fogo cruzado de uma reforma tributária que pretende simplificar os impostos indiretos, consolidando todas as contribuições de natureza tributária, o Imposto sobre Produtos Industrializados e o ICM S em imposto sobre o valor agregado (IVA) e na iminência de uma difícil votação sobre a continuidade da CPM F, a luta pela suficiência de recursos para o financiamento da Saúde parece longe de terminar.

A evolução da despesa do SUS com ações
e serviços públicos de saúde (1995/2006)

Passado pouco mais de uma década, a participação da despesa com ASPS no PIB em fins de 2006 erade $1,75 \%$, praticamentereproduzindo os percentuais observados em 1995, em que pese a expressiva mudança de patamar da carga tributária, centrada nas contribuições sociais. A evolução do gasto com Ações e Serviços Públicos de Saúde da União, que representava $9,64 \%$ da receita correnteem 1995, declinou nos anos seguin-

Tabela 2. Divisão federativa da receita tributária disponível.

\begin{tabular}{cccccc}
\hline & Carga & \multicolumn{4}{c}{ Divisão federativa - \% total } \\
\cline { 2 - 5 }$(\%$ do PIB $)$ & União & Estados & M unicípios & Soma \\
\hline 1965 & 19,71 & 55,7 & 35,1 & 9,2 & 100,0 \\
1988 & 22,43 & 60,1 & 26,6 & 13,3 & 100,0 \\
2005 & 38,94 & 57,6 & 25,2 & 17,2 & 100,0 \\
\hline
\end{tabular}

Fonte: Afonso \& M eirelles, 2006.

Arrecadação própria mais/menos repartição constitucional de impostos. 
tes atéatingir 6,98\%, (Tabela 3), refletindo o crescimento mais acelerado das receitas correntes visà-vis o indexador adotado para variação dos gastos federais com Saúde ${ }^{8}$.

$\mathrm{N}$ a vigência da EC 29,0 crescimento do gasto deveu-se principalmente à participação de estados e municípios. Para o crescimento nominal da ordem de $120 \%$ dos recursos totais para a saúde, estados e municípios apresentaram um crescimento superior a $170 \%$.

Com isso, a participação da União no gasto total, que chegou a ser de $70 \%$, declina eseaproxima de $50 \%$. O u seja, em que pese à dificuldade de financiamento no plano da base tributária própria dos estados e municípios, a força de EC 29 para solidificar o sistema único foi decisiva.
Perspectivas de regulamentação da EC 29

A regulamentação da emenda está centrada em três aspectos principais: a base de cálculo e/ou indexador para os gastos com ASPS, a definição constitucional dos gastos com ASPS, assim como das vedações correspondentes, e os critérios de repasse de recursos do SUS entre níveis de governo.

Quanto ao primeiro aspecto, sua importância para a suficiência de recursos do SUS é demonstrada pela comparação entre as despesas efetivamente real izadas pelo M inistério da Saúde e simulações que encerram as princi pais alternativas de revisão:

A comparação entre a evolução das receitas correntes brutas da União e as despesas com

Tabela 3. Evolução do PIB, das Receitas Correntes Brutas (RCB) da União e das despesas com Ações e Serviços Públicos de Saúde (ASPS) do M inistério da Saúde, 1995 a 2007 (em milhões R\$ nominais).

\begin{tabular}{ccccccc}
\hline Ano & PIB & RCB & RCB/PIB & ASPS & ASPS/RCB & ASPS/PIB \\
\hline 1995 & 705.641 & 127.094 & $18,0 \%$ & 12.257 & $9,6 \%$ & $1,74 \%$ \\
1996 & 843.966 & 156.830 & $18,6 \%$ & 12.407 & $7,9 \%$ & $1,47 \%$ \\
1997 & 939.147 & 175.270 & $18,7 \%$ & 15.464 & $8,8 \%$ & $1,65 \%$ \\
1998 & 979.270 & 200.455 & $20,5 \%$ & 15.245 & $7,6 \%$ & $1,56 \%$ \\
1999 & 1.065 .000 & 218.021 & $20,5 \%$ & 18.353 & $8,4 \%$ & $1,72 \%$ \\
2000 & 1.179 .482 & 252.519 & $21,4 \%$ & 20.351 & $8,1 \%$ & $1,73 \%$ \\
2001 & 1.302 .136 & 289.411 & $22,2 \%$ & 22.474 & $7,8 \%$ & $1,73 \%$ \\
2002 & 1.477 .822 & 343.075 & $23,2 \%$ & 24.737 & $7,2 \%$ & $1,67 \%$ \\
2003 & 1.699 .948 & 384.447 & $22,6 \%$ & 27.181 & $7,1 \%$ & $1,60 \%$ \\
2004 & 1.941 .498 & 450.590 & $23,2 \%$ & 32.703 & $7,3 \%$ & $1,68 \%$ \\
2005 & 2.147 .944 & 527.325 & $24,6 \%$ & 37.416 & $7,1 \%$ & $1,74 \%$ \\
2006 & 2.322 .818 & 584.067 & $25,1 \%$ & 40.751 & $7,0 \%$ & $1,75 \%$ \\
2007 & 2.523 .100 & 658.799 & $26,1 \%$ & 45.806 & $7,0 \%$ & $1,82 \%$ \\
\end{tabular}

Fonte: IBGE para PIB; STN para RCB eSPO/M S paraASPS.

Obs: Para 2007 o valor das RCB éo da estimativa de maio daSTN eo de ASPS corresponde ao da LOA.

Tabela 4. Recursos aplicados em ASPS por esfera de governo, 2000 a 2005 (em milhões R\$ nominais).

\begin{tabular}{lcccc}
\hline & União & Estados & Municípios & Total \\
\hline 2000 & $20.351,5$ & $6.313,4$ & $7.445,4$ & $34.110,3$ \\
2001 & $22.474,1$ & $8.269,8$ & $9.493,9$ & $40.237,8$ \\
2002 & $24.736,8$ & $10.078,5$ & $12.069,2$ & $46.884,5$ \\
2003 & $27.181,2$ & $12.224,3$ & $13.715,3$ & $53.120,8$ \\
2004 & $32.703,5$ & $16.220,7$ & $16.427,9$ & $65.352,1$ \\
2005 & $37.145,8$ & $17.230,9$ & $20.805,8$ & $75.182,5$ \\
\hline
\end{tabular}

Fonte: SIOPS/SCTIE/MS 
ASPS do M S em relação ao PIB nominal ésuficiente para sugerir a adoção da receita corrente como base de cálculo. Esta é a tônica das propostas em tramitação no Congresso Nacional. Cabe destacar a diferença potencial acumulada entre o gasto efetivo e o gasto com ASPS, caso a base de cálculo fosse $10 \%$ da Receita Corrente Bruta da União (proposta da PLP 01/2003). Neste cenário alternativo, o MS poderia ter gasto quase $\mathrm{R} \$ 80$ bilhões a mais do que efetivamente gastou no período 2000/2006 (Gráfico 2).

Quanto à definição constitucional de Ações e Serviços Públicos de Saúde, parece essencial re forçar as vedações, em particular quanto aos encargos previdenciários e aos gastos com saneamento, campos onde os governos estaduais não cumprem as determinações da emenda. No plano federal, em 2006, com basenas determinações da EC 29, o MS pôde expurgar as despesas do Programa FomeZero, que em parteeram indevidamente inseridas na programação da Saúde.

Com a destinação correta, houve aplicação de recursos em despesas realmente vinculadas às ações de Saúde, que apresentaram aumento de $\mathrm{R} \$ 6,2$ bilhões, equivalente a $18 \%$ da programação assistencial da Bolsa Família, que integra o Fome Zero ${ }^{5}$.

Quanto ao repasse de recursos para os governos subnacionais, a ameaça de mudança dos critérios do artigo 35 da lei 8.080 , referentes à alocação de recursos no interior do SUS, é preo- cupante, desde logo por ameaçar a sistemática de financiamento e de repasses do SUS, como um sistema único de natureza federativa, dotado de critérios alocativos próprios à Saúde

Tais critérios, constantemente aperfeiçoados, levam em conta o território e a regionalização das ações da saúde, a hierarquização dos serviços e a construção de redes, as necessidades e a demanda da população por serviços, as características epidemiológicas, as diferenças de capacidade de gestão deestados e municípios, os desníveis na oferta de serviço e as necessidades de investimentos, as características territoriais especiais (fronteiras, região amazônica, entre outras).

A eventual substituição de critérios baseados nos determinantes assinalados por critérios populacionais transformaria o M S em mero repassador de recursos aos governos subnacionais, ignorando as características de diferenciação intrínsecas à natureza das Ações e Serviços Públicos de Saúde.

Os incentivos financeiros

e o poder de indução do SUS

nas relações intergovernamentais

Astransferênciasintergovernamentaisno âmbito do SUS são formas de financiamento relevantes para um número maior de municípios e estados, alocados por várias parcelas, entre as quais predominam os programas de atenção

Gráfico 2. Gasto efetivo versus PLP, em janeiro de 2003.

R\$ bilhões Comparação: gasto efetivo x PLP 01/2003

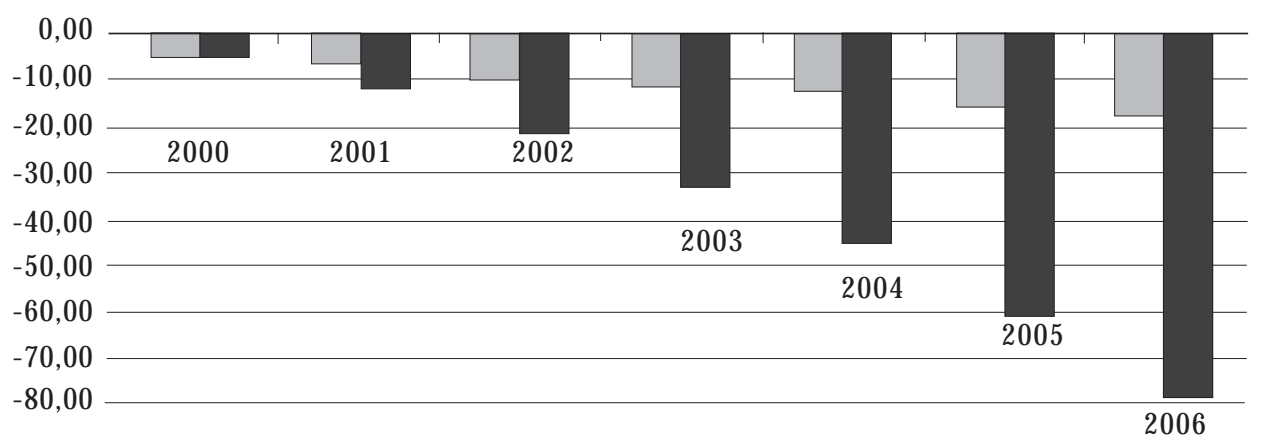


básica financiados pelo PAB variável e nas ações estratégicas financiadas pelo FAEC, que em conjunto representam as transferências mais dinâmicas da última década, no campo das relações intergovernamentais em saúde.

0 repasse de recursos favorece os municípios que desenvolvem os diferentes programas. Nesse sentido, o instrumento fundo a fundo tornase apenas um mecanismo contábil, reduzindo o governo local a mero receptor de recursos. Embora extremamentevariados, os incentivosfinanceiros não obedecem a critérios voltados para corrigir a heterogeneidadena oferta de organização einvestimento de redes de serviços?.

Para superar estes problemas, estão previstas alterações nas regras do financiamento do SUS, nas portarias que regem o Pacto pela Saúde. 0 Pacto aloca os recursos do MS destinados às ações e serviços descentralizados do SU S em cinco blocos definanciamento: Atenção Básica; Atenção deM édia eAlta ComplexidadeAmbulatorial e Hospitalar; Vigilância em Saúde; Assistência Farmacêutica; Gestão do SUS.

Essa medida podereduzir a fragmentação das transferências federais e aumentar a autonomia dos governos locais, apesar de quea distribuição dos recursos em cada bloco permanece inalterada, representando a agregação de incentivos financeiros anteriores, com critérios de transferência e uso definidos em portarias específicas.

Cabediscutir ainda sea diversidade decritérios consolidados em cada bloco garante à União as condições necessárias para a equalização fiscal das esferas subnacionais no campo do SUS e para a ampliação de sua capacidade de gasto em saúde.

A pesar das virtudes das transferências do SUS mantidas no Pacto pela Saúde (tais como o PAB fixo e o PAB variável eas transferências de média e alta complexidade), vários reparos podem ser feitos, sobretudo no campo da equidade.

Estudos baseados nas informações do Sistema de I nformações de Orçamentos Públicos em Saúde (SIOPS) em 2002 indicam que, apesar de tendência mais eqüitativa das transferências federais do SUS, a alocação destes recursos não superou as desigualdades inter e intra-regionais das receitas públicas munici pais, nem a situação desfavorável dos municípios médios 9 .

Subsistem ainda no SUS padrões inadequados de oferta, cobertura e gasto público em Ações eServiços de Saúde, denatureza, complexidadee custos diversos, e realidades regionais distintas, que os atuais incentivos financeiros não foram capazes de superar, entre outras razões, pelo excesso de fragmentação dos recursos.

\section{O financiamento do SUS no contexto das rel ações público privadas}

A separação entre o financiamento e a provisão de serviços

Por suas características históricas, a prestação deserviçoshospitalarescom financiamento público no Brasil vem operando predominantemente através de terceiros, sejam estes empresas privadas lucrativas, entidades beneficentes efilantrópicas, ou, ainda, hospitais universitáriose deensino.

Dessa forma, no nível federal do SUS, responsável historicamente pelo aporte de mais de $75 \%$ dos recursos financeiros setoriais, (hoje reduzidos a $50 \%$ por conta das vinculações pela EC 29 de recursos de estados e municípios), já existe a quase completa separação das funções de financiamento e provisão de serviços. Subsiste, entretanto uma relação de concorrência entre os segmentos público e privado, com superposição entre clientelas, tudo isso reforçando a necessidade de articulação entre os dois campos.

A distribuição da rede de serviços hospitalares pelo setor privado não éhomogênea em todo o território nacional, apresentado diferenças regionais, estaduais e por município, e por natureza das intervenções. Se bem seja verdade que a organização macro e microrregional das redes de serviços inclui o setor privado, há uma clara concentração da rede pública nas regiões $\mathrm{N}$ ortee Nordeste. A distribuição tampouco é homogê nea por porte de hospitais, funções, além do que a cobertura privada varia por nível de renda, faixa etária, gênero, porte de cidade, etc.

A principal explicação para esta heterogeneidade regional decorre da desigual configuração da saúde suplementar no território nacional. No plano dos governos subnacionais, fica claro que o descumprimento dos percentuais de vinculação previstos na EC 29 explica o subfinanciamento das Ações e Serviços Públicos de Saúde em vários estados da federação.

A isto se adiciona a limitação do M inistério da Saúde em aportar recursos de financiamento, ao financiamento às ações de média ealta complexidade. $\mathrm{N}$ as relações com a rede assistencial não estatal, verificam-se descompassos nas remunerações por procedimento, sendo as diferenças entre o valor real e o valor SUS apontadas na Tabela 5.

Desde meados dos anos 90, a tabela do SUS sofreu apenas correção de $37 \%$, frentea um crescimento do IGP-M de $318,10 \%$, e aumento de insumos estratégicos, como combustível e energia, entre $500 \%$ e $600 \%$. 
Tabela 5. Diferenças entre valor real e valor SUS.

\begin{tabular}{lccc}
\hline Procedimento & Valor SUS & Valor real & Diferença \\
\hline Consulta em especialidade adulta & 7,55 & 20,94 & $177,4 \%$ \\
Raio-x simples & 4,91 & 27,58 & $461,7 \%$ \\
Endoscopia & 14,41 & 79,67 & $452,9 \%$ \\
Diária de UTI - II & 213,71 & 720,00 & $238,0 \%$ \\
Insuficiência respiratória & 793,01 & $3.083,44$ & $288,8 \%$ \\
Pneumopatias agudas & $1.036,05$ & $2.047,63$ & $97,6 \%$ \\
Apendicectomia & 525,40 & $1.227,24$ & $143,0 \%$ \\
Toracotomia & $1.062,66$ & $3.322,04$ & $221,7 \%$ \\
\hline
\end{tabular}

No que respeita a dimensão regional da crise, os estados do Nordeste apresentam déficits financeiros superiores às demais regiões nos serviços de média e alta complexidade, acumulando volume significativo de demandas não atendidas pelo SU S, amplificando assim as diferenças regionais de acesso.

À sombra do Estado: o financiamento público dos planos de saúde

As relações público-privadas no âmbito do SUS levam à constatação de que o sistema de saúde privado de natureza lucrativa está submetido a duas ordens de regulação por parte do setor público, não necessariamente inspiradas na mesma lógica.

Em primeiro lugar, seu desempenho é afetado diretamente pelas tabelas de remuneração de procedimentos e demais custos definidos ou influenciados pelo SUS, como medicamentos, matérias hospitalares, salários de profissionais de saúde, etc., sem esquecer os investimentos diretos da órbita pública na rede própria e paraestatal, com impacto na oferta de serviços.

Deoutra parte, a regulação imposta pelaAgência Nacional de Saúde Suplementar (ANS) aos prestadores e operadores de saúde vem antecipando a necessidade de desenvolver ações de contratualização entre operadoras, hospitais, clínicas ambulatoriais e serviços auxiliares de diagnóstico eterapia, discutidascom a Agênciaa partir de 2004.

Ao consolidar todas as fontes de financiamento da atenção à saúde no Brasil, as fontes privadas superam as públicas, sendo também elevada a partici pação do gasto direto das famílias com assistência à saúde, mesmo se excluídas as despesas com o pagamento de mensalidades de planos de saúde pelas famílias ${ }^{10}$.
Os planos privados de assistência à saúde atuam no sistema de saúde brasileiro, comprometendo sua universalidade e configurando-se como mais um fator de geração de desigualdades sociais no acesso e na utilização de serviços de saúde, dado que cobrem apenas uma parcela específica da população brasileira, de maior renda familiar inserida no mercado de trabalho formal, nas capitais/regiões metropolitanas, em cidades de mais de 80.000 habitantes.

A marca da universalização do Sistema de Saúde no Brasil é que ela não configurou uma relação de complementaridade entre o setor público e o setor privado, havendo, ao contrário, concorrência entre os dois segmentos, apesar do peso direto e indireto dos recursos públicos ao financiamento da saúde suplementar.

A grande maioria dos planos de saúde no Brasil corresponde hoje a salários indiretos dos trabalhadores, com recursos alocados pelas empresas na categoria de custos operacionais. Isso explica o fato de que $70 \%$ dos contratos de planos de saúde sejam coletivos.

Assim, a matriz de financiamento dos gastos totais de saúde deve distinguir os recursos públicos, federais, estaduais e municipais e os recursos privados, de responsabilidade das famílias e das empresas.

A Tabela 6 revela que, em 2003, do total de 8,6\% do PIB hojegastosem Saúdeno Brasil, 3,5\% do PIB correspondem a gastos diretos do Estado, respondendo o setor privado por $5 \%$ do PIB, distribuídos entre planos de saúde (1,9\% do PIB) e gastos diretos das famílias (3,5\%).

Estes dados escondem o aporte indireto do setor público, tanto através da renúncia fiscal que beneficia indivíduos ou empresas, seja através o aporte direto de recursos do Tesouro aos planos de saúde de servidores. Os autores citados desta- 
Tabela 6. Estimativa dos gastos com saúde segundo fontes públicas e privadas por tipo de gasto (Brasil, 2002-2003, em milhões de reais).

\begin{tabular}{|c|c|c|c|c|}
\hline Tipo de gasto & Fontes & $\begin{array}{l}\text { Em milhões } \\
\text { de reais }\end{array}$ & $\%$ & $\%$ do $\mathrm{PIB}^{4}$ \\
\hline Sistema Único de Saúde (SUS) & $\begin{array}{l}\text { Impostos gerais e } \\
\text { contribuições sociais }{ }^{1} \\
\text { União } \\
\text { Estados } \\
\text { Municípios }\end{array}$ & $\begin{array}{l}46.574,00 \\
24.737,00 \\
10.078,00 \\
11.759,00\end{array}$ & $\begin{array}{r}43,85 \\
23,29 \\
9,49 \\
11,07\end{array}$ & 3,5 \\
\hline Planos de saúde privados & $\begin{array}{l}\text { Planos privados de saúde }{ }^{2} \\
\text { Gastos das famílias } \\
\text { Gastos das empresas }{ }^{3}\end{array}$ & $\begin{array}{l}26.497,00 \\
13.026,00 \\
13.471,00\end{array}$ & $\begin{array}{l}24,95 \\
12,26 \\
12,68\end{array}$ & 1,9 \\
\hline $\begin{array}{l}\text { Gastos diretos das famílias exceto } \\
\text { com planos privados de saúde }\end{array}$ & Desembolso direto ${ }^{4}$ & $33.149,00$ & 31,21 & 3,1 \\
\hline TOTAL & & $106.220,00$ & 100,00 & 8,6 \\
\hline
\end{tabular}

Elaboração: Cremesp/ldec.

Fontes: ${ }^{1}$ M inistério da Saúde, 2004; ${ }^{2}$ IBGE - Pesquisa de Orçamentos Familiares (POF) 2002-2003 e ANS, 2004. A estimativa dos gastos das empresas foi cal culada por meio da subtração dos gastos das famílias com planos privados do total do faturamento das empresas de planos e seguros de saúde declarado à AN S; ${ }^{3}$ IBGE - Pesquisa de O rçamento Familiar 2002-2003. A estimativa do desembolso direto foi calculada a partir das despesas das famílias com assistência à saúde (medicamentos, assistência médica e odontológica particular, etc...) excetuando as referentes ao pagamento de planos privados de saúde; ${ }^{4}$ PIB em $2002=\mathrm{R} \$ 1.321 .400$ milhões.

cam que a isso deveria ser agregado o financiamento dos planos de saúde de servidores de estatais, as significativas deduções referentes àsinstituições filantrópicas (Santas Casas, principalmente), que muitas vezes comercializam planos de saúde e se integram a rede de prestação de serviços de empresas de assistência suplementar (os valores apresentados não incluem os gastos dos governos estaduais e federais, nem os gastos das demais empresas estatais ).

Finalmente, deve-se destacar também o peso dos aportes do Tesouro, responsáveis por cerca de $50 \%$ do financiamento da Agência Nacional de Saúde Suplementar (ANS) ${ }^{10}$.

A Tabela 7 desagrega 0 total de gastos e deduções tributárias com planos de saúde no Brasil em 2005. Em que pese às dificuldades de compatibilização dos dados, fornece excelente aproximação a quantificação do "Estado invisível", apontando para o elevado grau de desmercantilização do setor privado.

O planejamento e financiamento do SUS requerem a articulação destas situações, até para redimensionamento dosleitos, ganhos deeficiência, formulação de incentivos e desincentivos (para penalizar o excesso de leitos, como na experiência internacional).

A adesão à contratualização, ao planejamento integrado e aos incentivos dispersos pelos vários programas do SU Sem nível federal eestadual poderia contribuir para a maior estabilidade das relações entre oferta e demanda, e para taxas de ocupação regulares e que minimizam situações de ineficiente uso da capaci dade instalada.

Os incentivos tributários, ou renúncia de arrecadação, pelos quais o setor público financia indiretamente o setor privado, não tornam imediatamente evidentes os setores e ações beneficiadas por tais despesas tributárias, evitando enfrentamentos frontais euma real explicitação das prioridades de gasto público. Em sociedades muito desiguais como o Brasil, esta estratégia pode abrigar uma escolha trágica esilenciosa entre os que terão acesso a serviços e os que serão mais uma vez excluídos.

\section{O poder de compra do SUS}

Até aqui, a análise dos aspectos do financiamento do SUS foi conduzida em termos de sua 
Tabela 7. Gastos e deduções tributárias com planos de saúde (Brasil, 2005).

\begin{tabular}{lrr}
\hline Gastos com planos e seguros de saúde & Valor (em 1000 R\$) & $\%$ \\
\hline Gastos com planos de saúde de servidores federais & $979.111,62$ & 2,51 \\
Gastos com planos de saúde das estatais selecionadas & $2.726 .000,00$ & 7,00 \\
Demais fontes (empresas empregadoras e famílias & $35.240 .888,38$ & 90,49 \\
Total de gastos com planos e seguros privados de saúde) & $38.946 .000,00$ & 100,00 \\
inclui os gastos com estatais selecionadas & & \\
\hline Deduções/Gastos tributários & & \\
Dedução/Gasto tributário IRPF (desp, med + planos de saúde) & $1.943 .016,78$ & 4,99 \\
Dedução/Gasto tributário IRPJ (desp, med + planos de saúde) & $725.171,08$ & 1,86 \\
\hline
\end{tabular}

Fontes: M inistério do Planejamento - Informações Complementares das Leis de Diretrizes Orçamentárias de 2005 e 2006; M inistério da Fazenda - Secretaria da Receita Federal (Coordenação-Geral de Política Tributária), 2006. Demonstrativo dos gastos governamentais indiretos de natureza tributária.

ação no contexto do sistema de proteção social brasileiro. Esta política pública de natureza universal e redistributiva tem, entretanto, grande impacto positivo sobre a economia brasileira.

Pela expressão de seu orçamento e pela coerência de suas intervenções no complexo industrial da Saúde, o SU S contribui para a geração de investimentos, inovações, renda, emprego e re cursos fiscais para o Estado brasileiro.

De acordo com o MS, em termos econômiCOS, a cadeia produtiva da saúde representa entre $7 \%$ e $8 \%$ do PIB, mobilizando um valor em torno de $R \$ 160$ bilhões. Emprega diretamente, com trabalhos qualificados formais, cerca de $10 \%$ da população brasileira e é a área de maior expressão no país de investimentos públicos com pesquisa e desenvolvimento. Em termos de empregos diretos e indiretos, em toda cadeia produtiva, o conjunto destas atividades representa cerca de 7,5 milhões de trabalhadores inseridos, predominantemente, em atividades intensivas em conhecimento ${ }^{8}$.

A integração entre as políticas voltadas para o desenvolvimento do sistema de saúde eaquelas voltadas para a promoção do desenvolvimento industrial e da inovação é também uma forma de garantir para o país os benefícios econômicos gerados pelos gastos em saúde, assegurando a continuidade da política social.

A própria garantia de demanda e de estabelecimento de legítimas relações de clientela com o setor privado supridor de insumos farmacêuticos, produtos médicos, produtos e equipamen- tos para exames, no âmbito da União, dos estados, do Distrito Federal edos municípios éem si mesma uma ação redutora de custos e preços, e de fixação e desenvolvimento do setor empesarial, público ou privado, que abastece o SUS.

M as esta é apenas uma visão estática do problema, uma vez que o SUS, por sua integração à Política Industrial, Tecnológica e de Comércio Exterior do governo federal, pode usar seu poder de compra no estimulo à inovação e o desenvolvimento tecnológico.

Do ponto de vista do financiamento, o sistema nacional de Ciência e Tecnologia, ao qual o SU S se integra, já utiliza mecanismos de indução, como incentivos fiscais; investimentos em pesquisa e desenvolvimento ( $P \& D$ ); créditos subsidiados, além da intervenção direta do Estado no processo produtivo e na formação de parcerias público-privadas.

A dinâmica industrial do complexo éem parte determinada pelo Estado, em função de seu poder de compra de bens e serviços e de seu poder de indução.

Há campo para o desenvolvimento de uma política específica, que ajude as empresas a antecipar e se adaptar aos fatores críticos de sucesso em seu mercado, articulando a dimensão sanitária e a dimensão econômica, a forma de operação e organização do sistema de saúde à dinâmica dos setores de atividade das inovações.

0 contraste entre as conseqüências da renúncia de arrecadação dirigida à Saúde Suplementar e o poder dosincentivos fiscais, do crédito edo gas- 
to público em Saúde sobre a cadeia virtuosa de política social, política industrial etecnológica fala por só e permite terminar com uma nota otimista este percurso nada simples pelos mundos complexos no financiamento da Saúde brasileira.

\section{Conclusões}

O OSS (orçamento da Seguridade Social) não representou moldura institucional capaz de garantir um padrão definanciamento estável à Saúde, nem de apropriar o dinamismo das contribuições sociais em termos de arrecadação. Dada a alternância das fontes, parece uma excelente estratégia a fidelização da receita da União (PLP 01/2003), sobretudo no contexto de uma nova reforma tributária.

A adoção da receita corrente bruta como base de cálculo proposta é certamente a alternativa mais promissora para a Saúde, por associar sustentabilidade e estabilidade, em caso de flutuações cíclicas, não garantidas por cada receita isoladamente.

A mudança de patamar de gastos que se associa à receita corrente bruta permite o reforço das relações intergovernamentais que expressam a solidariedade federativa do SUS. Entretanto, a partilha de receitas e de encargos de governo em saúde deveria ser estabelecida a partir decritérios internos à lógica do SUS.

O SU S não poderá conviver com a supressão de receitas nem com a adulteração do conceito de Ações eServiços Públicos de Saúde. Em síntese, a regulamentação da EC 29 não pode estar dissociada dos princípios constitucionais sobre os quais se fundamenta o SUS.

A reivindicação do SUS pelo seu direito ao financiamento suficiente esustentável nada mais é do que a necessidade de honrar seu compromisso junto à população brasileira, materializando a saúde como direito social e garantindo 0 acesso a e a utilização de serviços. Para tanto, requer que sejam viabilizados, depois de duas décadas, recursos para seu custeio e para investimentos que corrigirão as desigualdades na oferta de infra-estrutura de Saúde em todo o território nacional.

Gasto em saúde não é sinônimo de desperdício de recursos. Assim, os gestores da Saúde, em todos os níveis de governo, devem zela pela qualidade de seu gasto e pela racionalização e redução de seus custos. M ais ainda, devem atuar na revisão dos mecanismos de renúncia fiscal e outras formas de financiamento público ao setor supletivo de saúde, de modo a criar contrapartidas e reforçar o papel da regulação estatal sobre o sistema de saúde como um todo.

Em função de seu impacto macroeconômico sobre a renda, o emprego, o produto nacional e o gasto público, o SU S e o Estado podem usar os mecanismos de financiamento direto e indireto ao setor privado para estimular ações no campo do desenvolvimento industrial edainovação tecnológica, com impacto positivo sobre a competitividade da indústria nacional e a garantia de oferta de insumos, medicamentos e equipamentos de Saúde, democratizando o acesso da população aos bens e serviços necessários a sua sobrevivência saudável edigna. 


\section{Referências}

1. Dain S. Do direito social à mercadoria [tese]. Rio de Janeiro: IMS/U niversidade do Estado do Rio de Janeiro; 2000

2. Lima LD. Relações fiscais e financiamento do SUS: breve balanço do Pacto pela Saúde e construção de alternativas para a partilha intergovernamental de recursos na saúde. Setembro de 2007. [mimeo]

3. Instituto de Pesquisa Econômica Aplicada. Boletim de Políticas Sociais - Acompanhamento e A nálise 2007. Edição Especial no 13. Brasília: IPEA; 2007.

4. Ugá MAD, Marques RM. $O$ financiamento do SUS: trajetória, contexto e constrangimentos. In: Trindade N, Gerschman S, Edler F, Suárez J, organizadores. Saúde e democracia: história e perspectivas do SUS. Rio de Janeiro: Editora Fiocruz; 2005. p. 193-233.

5. Associação Nacional dos Auditores Fiscais da Receita Federal do Brasil. Análise da Seguridade Social em 2006. Braślia: Fundação ANFIP de Estudos de Seguridade Social; 2007.

6. Brasil. Ministério da Saúde. Seminário a Separação do Financiamento e da Provisão de Serviços no Sistema Único de Saúde Rio de Janeiro, 13 e 14 de abril de 1999. Brasília: M inistério da Saúde/ Banco Mundial; 2001. [Série D - Reuniões e Conferências; $n^{0}{ }^{6}$ ]
7. Vianna SW, Magalhães LCG, Silveira FG, Tomich FA. Carga tributária direta e indireta sobre as unidades familiares no Brasil: avaliação de sua incidência nas grandes regiões urbanas em 1996. Brasília: IPEA; 2000. [Texto para discussão 757]

8. Brasil. Ministério da Saúde. Secretaria de Ciência, Tecnologia e Insumos Estratégicos. Evolução da despesa do SUS com ações e serviços públicos de saúde. Brasília: M inistério da Saúde; 2007.

9. Lima L D. Federalismo, relações fiscais e financiamento do Sistema Ú nico de Saúde, a distribuição de receitas vinculadas á saúde nos orçamentos municipais e estaduais. Brasília: Editora Museu da República; 2007.

10. Azevedo Júnior R, organizador. Planos de Saúde: nove anos após a Lei 9.656/9. São Paulo: Conselho Regional de Medicina do Estado de São Paulo e Instituto Brasileiro de Defesa do Consumidor; 2007.p.69-79.

Artigo apresentado em 03/09/2007

A provado em 01/10/2007

Versão final apresentada em 19/10/2007 